\title{
Coordination Analysis and Scale Forecast of Urban Population Growth and Land Expansion in Henan Province
}

\author{
Zhao Xiuyan ${ }^{1}$, Zhou Pengchao ${ }^{2}$, Yang Yongfang, ${ }^{1, *}$ \\ ${ }^{1}$ College of Environment and Planning, Henan University, Kaifeng, China \\ ${ }^{2}$ School of Surveying and Urban Spatial Information, Henan University of Urban Construction, Pingdingshan, China \\ Email address: \\ 591222869@qq.com (Zhao Xiuyan), 1075384076@qq.com (Zhou Pengchao), yyfnp@henu.edu.cn (Yang Yongfang) \\ ${ }^{*}$ Corresponding author
}

\section{To cite this article:}

Zhao Xiuyan, Zhou Pengchao, Yang Yongfang. Coordination Analysis and Scale Forecast of Urban Population Growth and Land Expansion in Henan Province. American Journal of Environmental and Resource Economics. Vol. 3, No. 2, 2018, pp. 18-30. doi: 10.11648/j.ajere.20180302.12

Received: August 23, 2018; Accepted: September 11, 2018; Published: October 12, 2018

\begin{abstract}
With the rapid development of urbanization in Henan Province, it is of great significance to study the relationship between man and land in regional cities to grasp the quality of urban development and to promote the healthy development of urbanization. In this paper, data envelopment analysis (DEA), Kernel density analysis, gravity center model and Logistic model are used to analyze the evolution and coordination of urban population growth and land expansion in 18 cities of Henan Province from 2000 to 2014, and to predict their overall development trend. The results show that: (1) the urban land expansion rate in Henan Province is faster than the population growth rate on the whole, the spatial distribution of the two increment is mainly in Zhengzhou, Luoyang, Luohe and other core cities, and Anyang, Nanyang, Nanyang, etc. (2) the center of gravity of urban population and the center of gravity of land are both located in the southeast of Zhengzhou City, and the coordination relationship between them presents the situation of "Enhancement, Stability and Enhancement"; The spatial coordination between urban land expansion and population growth is weak, and the land advance development is the main factor. (3) before 2003, the urban population growth and land expansion kept in sync, The forecasting results show that slowing down the expansion of urban land properly and coordinating the relationship between human and land will be the future direction of urbanization in Henan Province.
\end{abstract}

Keywords: Henan Province, Data Envelope Analysis, Coordinated, Logistic Prediction

\section{Introduction}

Since the reform and opening up, China's economy has been growing rapidly, population urbanization and land urbanization process become accelerated significantly, and the speed and scale of urbanization are unprecedented [1] (Chan and Yao, 1999). The urban population of China increased from 89.4 million in 1980 to 429.53 million in 2014 , with the average annual growth rate of $4.72 \%$; the urban construction land area increased from $6,720 \mathrm{~km}^{2}$ in 1980 to $49,982.74 \mathrm{~km}^{2}$ in 2014, with the average annual growth rate of $6.08 \%$, indicating land expansion much faster than population growth. The ultimate goal of China's urbanization is to promote the sustained, rapid and sound development of the national economy, and finally realize the coordinated development and common prosperity of urban and rural areas [2] (Chen et al., 2016). However, in the process of rapid urban expansion, there appears the problem of incomplete urbanization, characterized by the population urbanization lagging behind the land urbanization [3] (Lyu et al., 2016), leading to redistribution of population in space [4] (Niu et al., 2014), leaving a far-reaching impact on coordinated development of resources, environment, economy and society [5] (Feng et al., 2014), even bringing about a series of problems such as empty cities. Lu (2007) stated that China's urbanization is actually false [6], poor and aggressive urbanization with out-of-control situation in space. Now, China remains at the key stage of rapid development of urbanization. The imbalance between man and land leads to sporadic development of cities and threatens sound development of urbanization. Thus, how to coordinate the relationship between population growth and 
land expansion is a major issue in the promotion of new urbanization in China [7] (Yang et al., 2013).

At present, studies of the coordination between population growth and land expansion mainly focus on two aspects. One is the measure of external coordination between population growth and land expansion. Chinese scholars carried out speed comparison and spatial evolution analysis on urban population growth and land expansion of different regions and scale mainly using international experience value methods such as allometric model and elasticity coefficient of urban land expansion. Scholars Chen (2014), Fu (2015), and Wang (2016) made empirical studies on the allometric relationship between urban population growth and urban land use [8-10]; Yang (2013), and Zhou (2016) improved the elasticity coefficient model for urban land expansion and added the per capita urban land constraint parameter $[7,11]$, to measure the coordination between urban land expansion and population growth. According to their studies, the urban land expansion speed was higher than the population growth rate in most cities, and their development was not coordinated. Although the above methods take into account the changes in relationship between the urban population and the land, at different economic development level and in different context, the quantitative matching relationship between them is different; thus, there will be misunderstanding if directly referring to the model parameters as empirical rules [12] (Chen et al., 2013). The other aspect is the measure of internal coordination between population growth and land expansion. From the perspective of urbanization, the evaluation system was established from the aspects of society, economy, ecology and sustainable development. The coupling coordination degree model was used to measure the coupling coordination relationship between urban population growth and land expansion. From different points of view and different regions, Fan (2014), Lyu (2016), and Cui (2014) made a spatio-temproal analysis on the coupling coordination between population urbanization and land urbanization $[13,3,14]$, discussed factors influencing their relationship, and came up with pertinent measures and recommendations. However, the coupling coordination degree model is to make evaluation based on proportional changes in various dimensions, which is not consistent with the objective fact that the urban system is a complex non-linear system and remains dynamically changing [15] (Huang and Feng, 2015).

Based on this, taking 18 cities above the prefecture level in Henan Province as research object, using the data envelope analysis (DEA) method, and introducing economic development constraints, we established the urban population and area coordination evaluation model using relatively independent but not inclusive variables such as urban population, built-up area, and GDP. Combined with Kernel density analysis and the center of gravity model, we revealed the population growth, land expansion, spatial change and coordination relationship of 18 cities in Henan Province in 2000-2014, and predicted the urban population and built-up area using Logistic model, to provide certain reference for understanding the spatial and temporal evolution process and future development trend of the relationship between urban population and land area, and properly regulating and control the population-land relationship.

\section{Study Method and Data Source}

\subsection{Research Methods}

\subsubsection{Kernel Density Analysis}

Kernel density analysis is to calculate the data aggregation of the entire region according to the input element data, so as to generate a continuous density surface [16] (Zhong et al., 2016). Using Kernel density analysis, it can visually reflect the spatial density distribution and variation trend of urban population and built-up area of 18 cities in Henan Province in 2000-2014. The specific calculation formula is as follows:

$$
f(x)=\frac{1}{n h} \sum_{i}^{n} \frac{K\left(x_{i}-x\right)}{h}
$$

where $n$ is the number of research regions, $i=1,2, \ldots, n ; h$ is bandwidth; $K\left(x_{\mathrm{i}}-x\right)$ is the stochastic kernel estimation function.

\subsubsection{Overall Coordination Measure Model}

In this study, we employed the center of gravity model and spatial coupling trend of the center of gravity to reflect the overall coupling trend of land expansion and population growth of 18 cities in Henan Province. The center of gravity model for land expansion and population growth is as follows:

$$
\begin{array}{r}
G_{A}(x, y)=\frac{\sum_{i}^{n} A_{i}\left(Q\left(x_{i}, y_{i}\right)\right)}{\sum_{i}^{n} A_{i}} \\
G_{P}(x, y)=\frac{\sum_{i}^{n} P_{i}\left(Q\left(x_{i}, y_{i}\right)\right)}{\sum_{i}^{n} P_{i}}
\end{array}
$$

where $G_{A}$ and $G_{P}$ denote the center of gravity of urban land and population respectively; $n$ is the number of research regions; $A_{i}$ and $P_{i}$ denote the built-up area and the year end population of the $i$-th city; $x_{i}$ and $y_{i}$ are the latitude and longitude of the $i$-the city.

Using the overlapping of spatial distribution and the consistency in movement track of center of gravity, we observed the spatial coupling trend in center of gravity o18 cities in Henan Province. The overlapping of spatial distribution can be calculated with the following formula (Zhou et al., 2016):

$$
S=d\left(G_{A}, G_{P}\right)=\sqrt{\left(X_{A}-X_{P}\right)^{2}+\left(Y_{A}-Y_{P}\right)^{2}}
$$

where $S$ refers to the distance between the center of gravity of urban population and that of urban land, $X$ and $Y$ denote the latitude and longitude of the center of gravity; the closer the distance, the higher the overlapping. 
The calculation formula for consistency in movement track of center of gravity is as follows (Zhou et al., 2016):

$$
\mathrm{C}=\cos \theta=\frac{\left(\Delta \mathrm{X}_{\mathrm{A}} \Delta \mathrm{X}_{\mathrm{P}}\right)+\left(\Delta \mathrm{Y}_{\mathrm{A}} \Delta \mathrm{Y}_{\mathrm{P}}\right)}{\sqrt{\left(\Delta \mathrm{X}_{\mathrm{A}}^{2}+\Delta \mathrm{Y}_{\mathrm{A}}^{2}\right)+\left(\Delta \mathrm{X}_{\mathrm{P}}^{2}+\Delta \mathrm{Y}_{\mathrm{P}}^{2}\right)}}
$$

where $\cos \theta$ denotes the cosine value of the vector angle of displacement of the center of gravity of urban population and land in this time point relative to that in last time point, and $\cos \theta$ is in the range of $[-1,1], 1$ means completely the same direction and -1 means completely opposite direction, the greater the value, the more consistent the variation; $\Delta X$ and $\Delta Y$ denote variation of the latitude and longitude of the center of gravity of this time point relative to the last time point.

\subsubsection{Spatial Coordination Measure Model}

In this study, we took the GDP of 18 cities in these years as the output factors of the system, and took the urban population and built-up area as the input factors of the system. Using the input-oriented CCR DEA model in DEAP 2.1 software, we obtained the optimal relationship between urban population, built-up area, and GDP on the condition that GDP is not changed. The calculation formula for the input-oriented CCR DEA model is as follows:

$$
\left\{\begin{array}{l}
\min \theta=V_{D} \\
\sum_{j=1}^{n} K_{j} X_{j}+S^{-}=\theta X_{0} \\
\sum_{j=1}^{n} K_{j} Y_{j}+S^{+}=Y_{0} \\
K_{j} \geq 0, j=1, \ldots n . \\
S^{-} \geq 0, S^{+} \geq 0 .
\end{array}\right.
$$

where $X_{j}$ and $Y_{j}$ are input and output indicators; $K_{j}$ is unit combination coefficient; as judgment criterion for assessing the relative effectiveness of DMU, $\theta$ is the relative efficiency value calculated by the model; $\mathrm{S}^{-}$and $\mathrm{S}^{+}$are slack variables [17] (Tian and $\mathrm{Xu}, 2012$ ). We compared the proportional relationship between ideal urban population and built-up area obtained through DEA model with that between actual urban population and built-up area, to measure the coordination between urban population and built-up area. The calculation formula is as follows:

$$
\mathrm{C}=\frac{\mathrm{L}_{\mathrm{i}}}{\mathrm{P}_{\mathrm{i}}} / \frac{\mathrm{L}_{0}}{\mathrm{P}_{0}}
$$

where $C$ denotes the scale coordination between urban population and area, $L_{\mathrm{i}}$ and $P_{\mathrm{i}}$ denote the actual urban built-up area and population, $L_{0}$ and $P_{0}$ denote the ideal built-up area and population. As per $\mathrm{C} \leq 0.5,0.5<\mathrm{C} \leq 0.86,0.86<\mathrm{C} \leq 1.24$, $1.24<\mathrm{C} \leq 1.6$, and $\mathrm{C}>1.6$, we divided the degree of coordination between urban population and land into five types: population significantly excessive, population obviously excessive, population-land basically coordinated, land obviously excessive, and land significantly excessive.

\subsubsection{Logistic Prediction Model}

The growth of many natural and social phenomena takes on an S-shaped curve. According to theoretical and empirical studies of the changes in urbanization level with time made by the United Nations [18] (1974), the changes in urbanization level with time take on an S-shaped curve, namely, changes in urban population and land also have the characteristics of S-shaped curve. Logistic function is a major method for describing such characteristics [19] (Chen, 2009).

$$
\mathrm{S}_{\mathrm{t}}=\frac{\mathrm{S}_{\max }}{1+\left(\mathrm{S}_{\max } / \mathrm{S}_{0}-1\right) \mathrm{e}^{-\mathrm{k}_{\mathrm{S}} \mathrm{t}}}
$$

where $S_{\max }$ denotes the maximum value of the simulated object (parameter of capacity or load); $k_{\mathrm{s}}$ denotes the initial growth rate of simulated object; $t$ is time series. When $t$ was not high, the Logistic growth model was about an exponential growth model.

\subsection{Data Source}

The basic data in this study mainly included population, land, and economy. The population data were the year end population (expressed in ten thousand) of the cities, the land data were the built-up area $\left(\mathrm{km}^{2}\right)$ of the cities, the economy data were GDP (expressed in 100 million yuan) of the cities. These data were selected from China City Statistical Yearbook and Statistical Yearbook of Henan Province (1986-1994, 2001-2015); Zhengzhou City had large floating population, so we took the permanent population of Zhengzhou issued by Zhengzhou Statistical Bureau as the population of Zhengzhou.

\section{Result Analysis}

\subsection{Characteristics of Urban Population and Land Evolution in Henan Province}

\subsubsection{Characteristics of Population Growth and Land Expansion Based on Time Series}

In 2000-2014, the urban population and land scale of Henan Province showed a linear growth trend. Specifically, the population increased from 15.18 million to 22.27 million, with the average annual growth rate of $2.78 \%$; land scale rose from $806 \mathrm{~km}^{2}$ to $1921 \mathrm{~km}^{2}$, with the average annual growth rate of $6.4 \%$; the ratio of their average annual growth rate was $1: 2.3$, much higher than 1:1.12 widely recognized by domestic scholars [20] (Liu et al., 2005), indicating that the land expansion was significantly faster than the population growth, urban population density declined year by year from 18,800 people $/ \mathrm{km}^{2}$ to 11,600 people $/ \mathrm{km}^{2}$, and the relationship between them went out of balance.

\subsubsection{Characteristics of Spatial Evolution}

Kernel density analysis can well show the spatial and temporal evolution of urban population and land in Henan Province. From the analysis on the Kernel density of the urban population and land of 18 cities in Henan Province in 2000, 2014 and 2000-2014, it can be known that (Figure 1): 

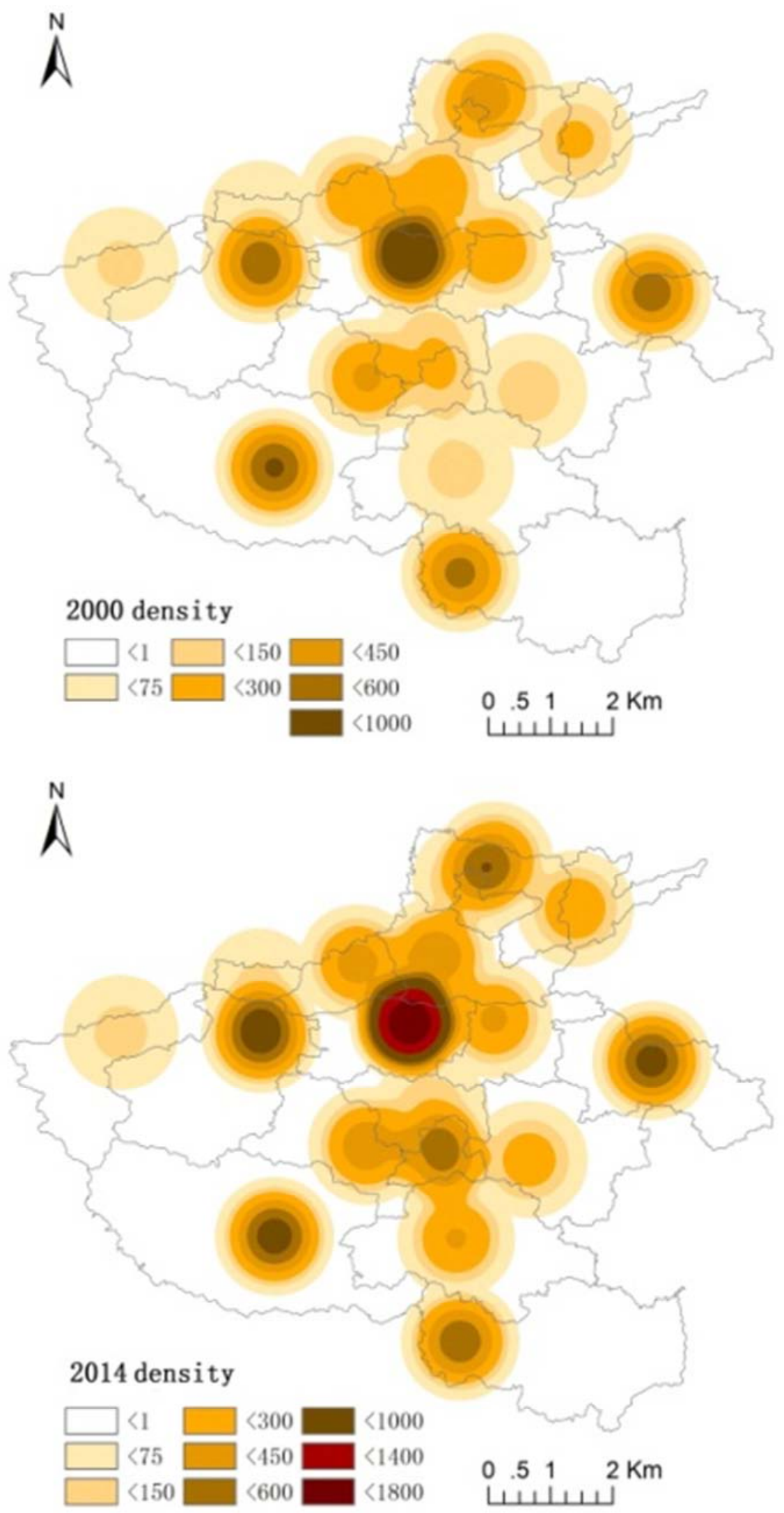


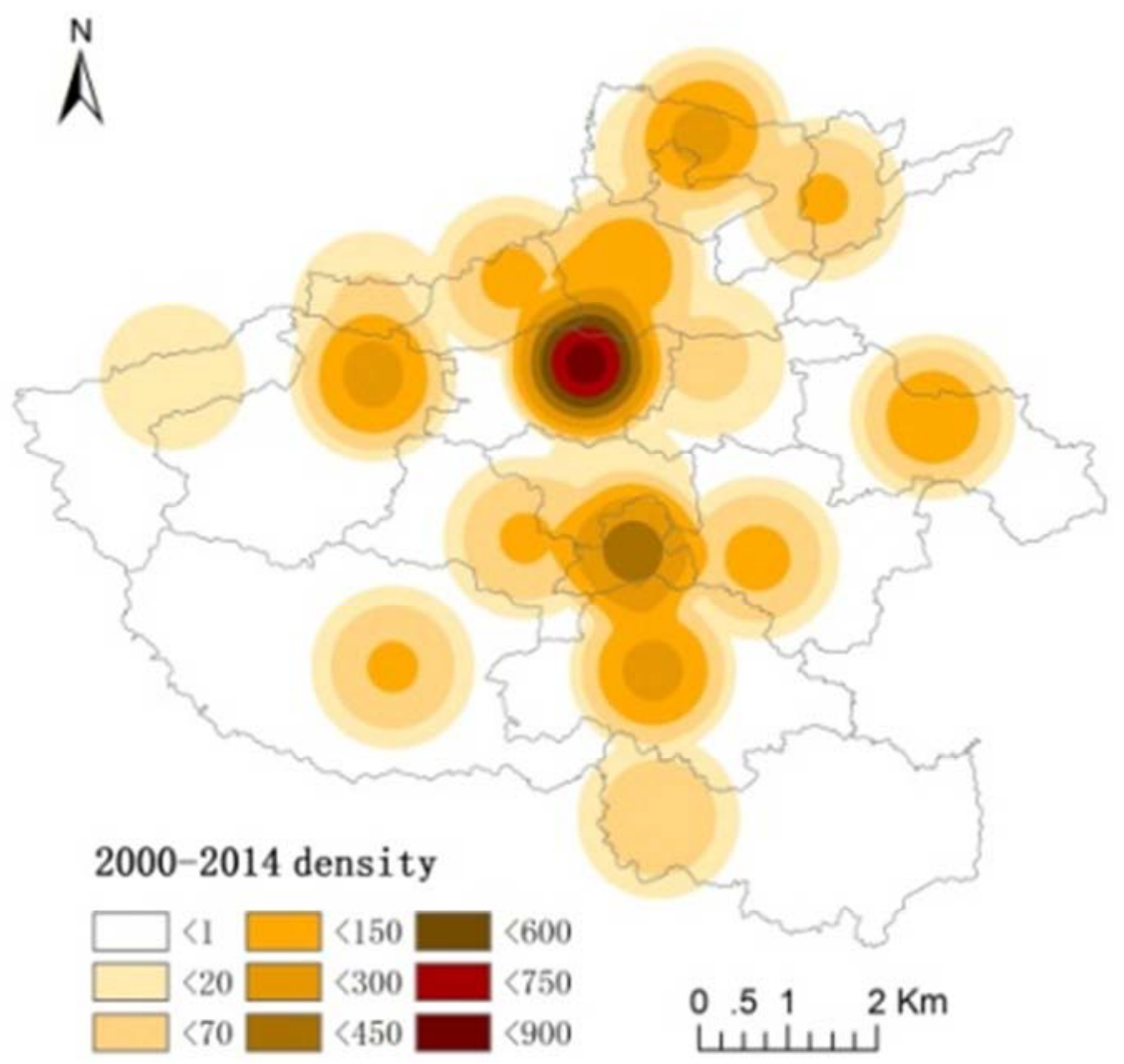

Figure 1. Spatial characteristics of Kernel density of urban population in Henan Province.

(1) The spatial distribution pattern of urban population: in 2000, the population density of cities in Henan Province was generally low, the population was mainly concentrated in single core circle with Zhengzhou as the center and Luoyang as the sub-center, and population density was in the range of 600-1,000; next, the population was mainly distributed in edge cities including Xinyang, Nanyang, Shangqiu, and Anyang, taking on independently decentralized distribution, and the population density was below 600; in other cities of Henan Province, the population was relatively little, the population density was below 300 , and the urbanization level was very low. In 2014, the urban population density of Henan Province increased significantly, with the maximum population density rising from 1,000 to 1,800 , showing the population agglomeration in a multi-core and edge form. The urban population was mainly concentrated in the city circle with Zhengzhou as the center and Luoyang as the sub-center, and the population density was in the range of 1,000-1,800; the next was the city circle with Luohe as the center, and the population density was in the range of 300-600; the last was edge cities such as Anyang, Xinyang, Nanyang, and Shangqiu, and the population density was in the range of 800-1000. In 2000-2014, urban population growth was mainly concentrated in city circle with Zhengzhou and Luohe as the center, and edge cities such as Anyang and Shangqiu. On the whole, the urban population in Henan Province grew rapidly, and the distribution of urban population formed two circles. First, it is the Central Plains core urban circle with Zhengzhou and Luoyang as the main core and Luohe as the sub-core, mainly rapid growth of the single core,
Zhengzhou. Second, it is peripheral radiated area consisted of edge cities such as Nanyang, Xinyang, Shangqiu, and Anyang, where the population grew rapidly and population density was uniformly distributed.

(2) The pattern of spatial distribution of urban land: in 2000, the urban land density in Henan Province was relatively low, and the spatial distribution was more centralized. It formed the "one-core two-wing" urban land distribution pattern with Zhengzhou as the center and Luoyang and Anyang as the sub-center and the urban land density of 300-600; the land density of other cities was below 150. In 2014, the urban land density of Henan Province rose rapidly, and the maximum density rose from 600 to 1,600 , the growth rate of urban land density was higher than that of urban population density. The range of core area was further expanded. It basically established a triangular distribution pattern with Zhengzhou as the center, and Luoyang, Luohe, and Anyang as the vertices. As the local growth core, Nanyang and Xinyang also showed high growth rate of urban land, and the urban land density also rose by 2-3 grades. Other cities also realized rapid growth. In 2000-2014, urban land expansion was still concentrated in city clusters with Zhengzhou and Luohe as the center and surrounding cities such as Anyang and Nanyang. Compared with the population growth, urban land expansion was faster. On the whole, the urban land expansion was faster than the population growth rate, but the distribution of urban land density was basically consistent with the distribution of population density, indicating that there is a high correlation between the urban population growth and land expansion. 

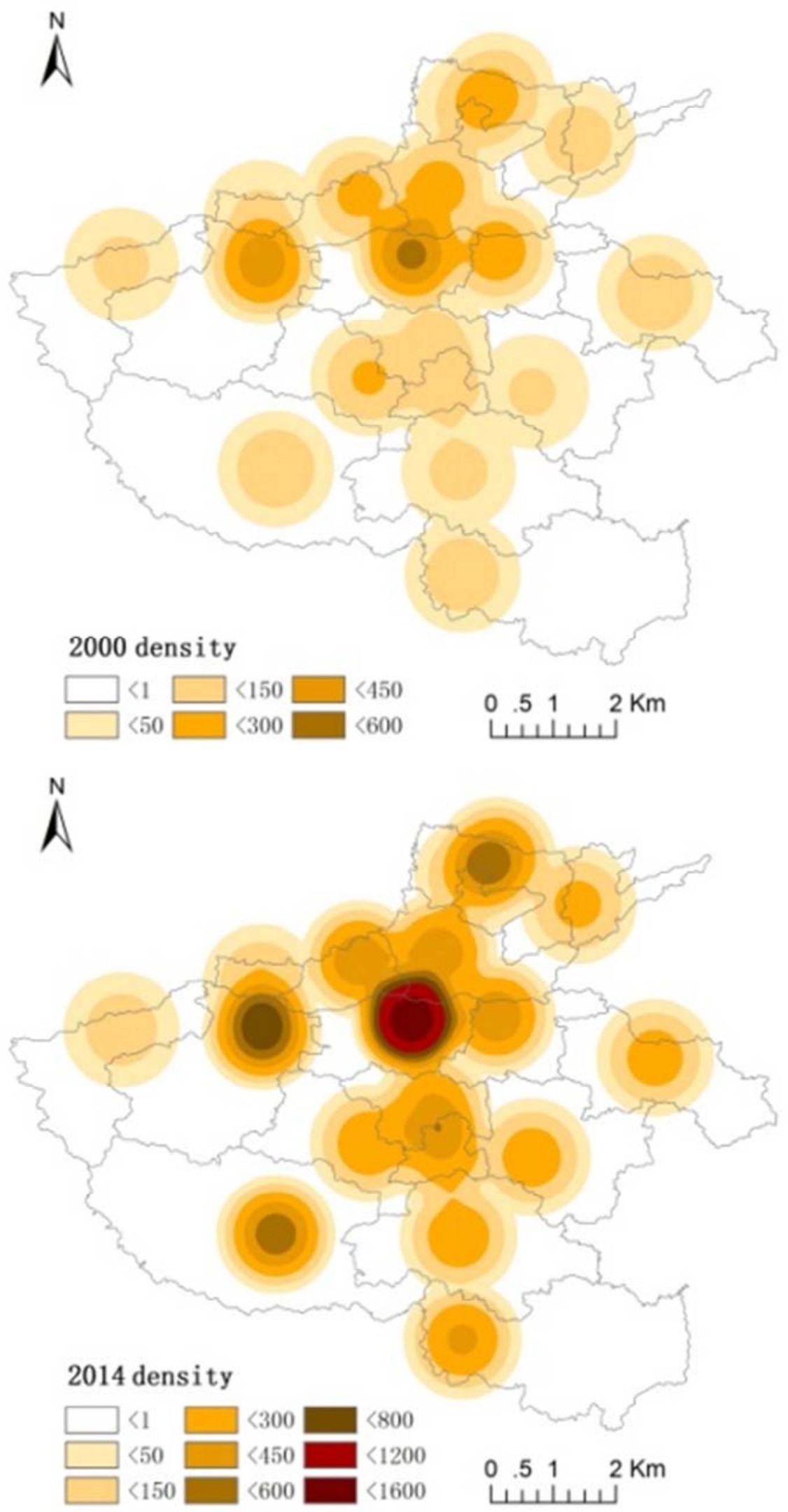


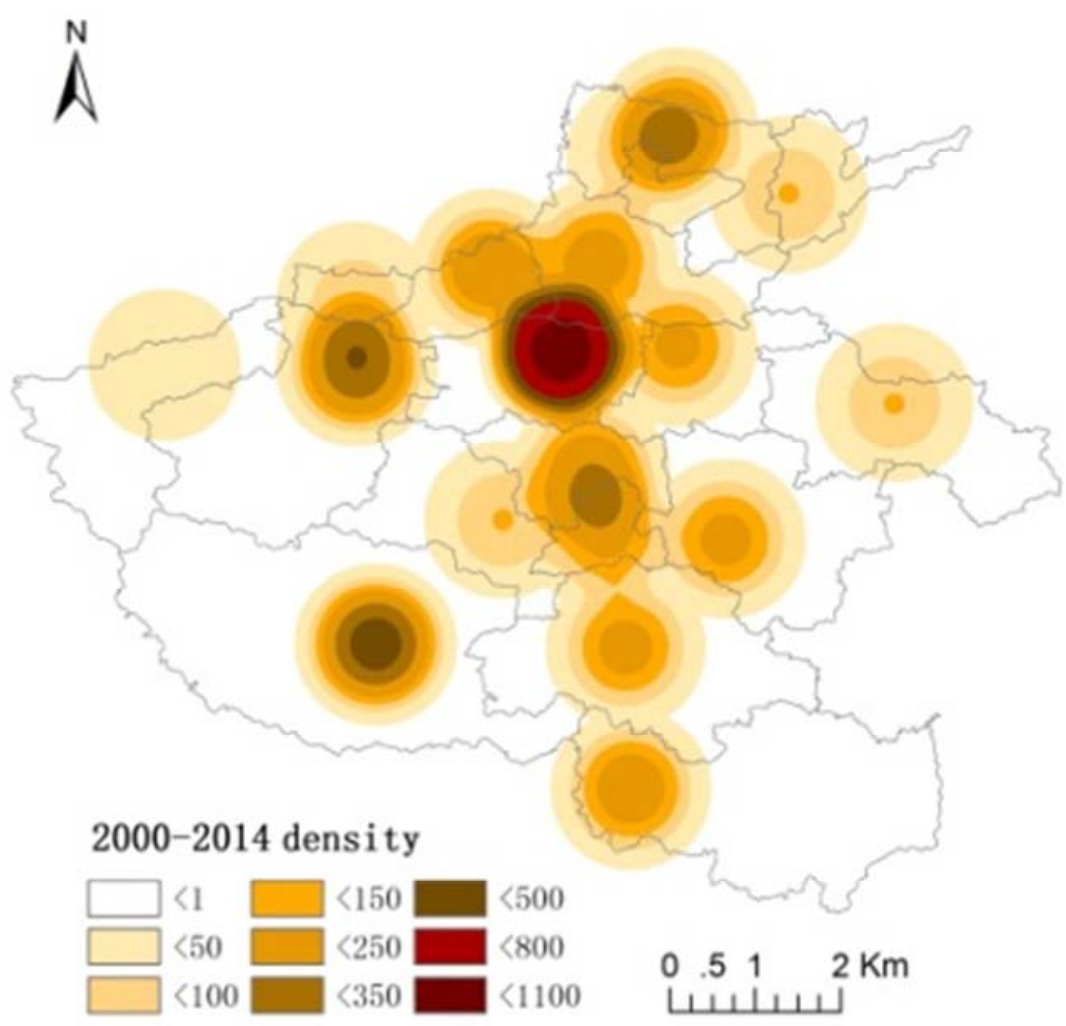

Figure 2. Spatial characteristics of Kernel density of urban land in Henan Province.

\subsection{Trend of the Coordination Between Urban Population and Land}

\subsubsection{Trend of the Overall Coordination}

Results of the movement track of center of gravity of urban population and land, spatial overlapping, and variation consistency were shown in Figure 3 and Figure 4.

(1) Movement track of center of gravity of urban population and land: the center of gravity of both urban population and built-up area in Henan Province was in southeast of Zhengzhou. Specifically, the center of gravity of built-up area was about $26 \mathrm{~km}$ from Zhengzhou downtown, while the center of gravity of population was about $49.5 \mathrm{~km}$ from Zhengzhou downtown. Combined with Figure 1, it can be known that the built-up area was mainly concentrated in the core city cluster with Zhengzhou as the center, but the center of gravity was near Zhengzhou. The distribution of center of gravity of urban population was influenced by eastern and southern large cities such as Nanyang, Xinyang, and Shangqiu, and the distribution of center of gravity greatly moved towards southeast of Zhengzhou. In 2000-2014, the center of gravity of urban population moved $4.69 \mathrm{~km}$ to the northeast, the distance of movement was small, and the annual average movement distance was $1.7 \mathrm{~km}$; the center of gravity of urban land moved $13.32 \mathrm{~km}$ to the south, the movement distance was large, about 2.84 times that of center of gravity of population, the annual average movement distance was $2.15 \mathrm{~km}$, indicating that the population and economic development were relatively stable in 18 cities of Henan Province, while the expansion of urban built-up area showed large fluctuation.

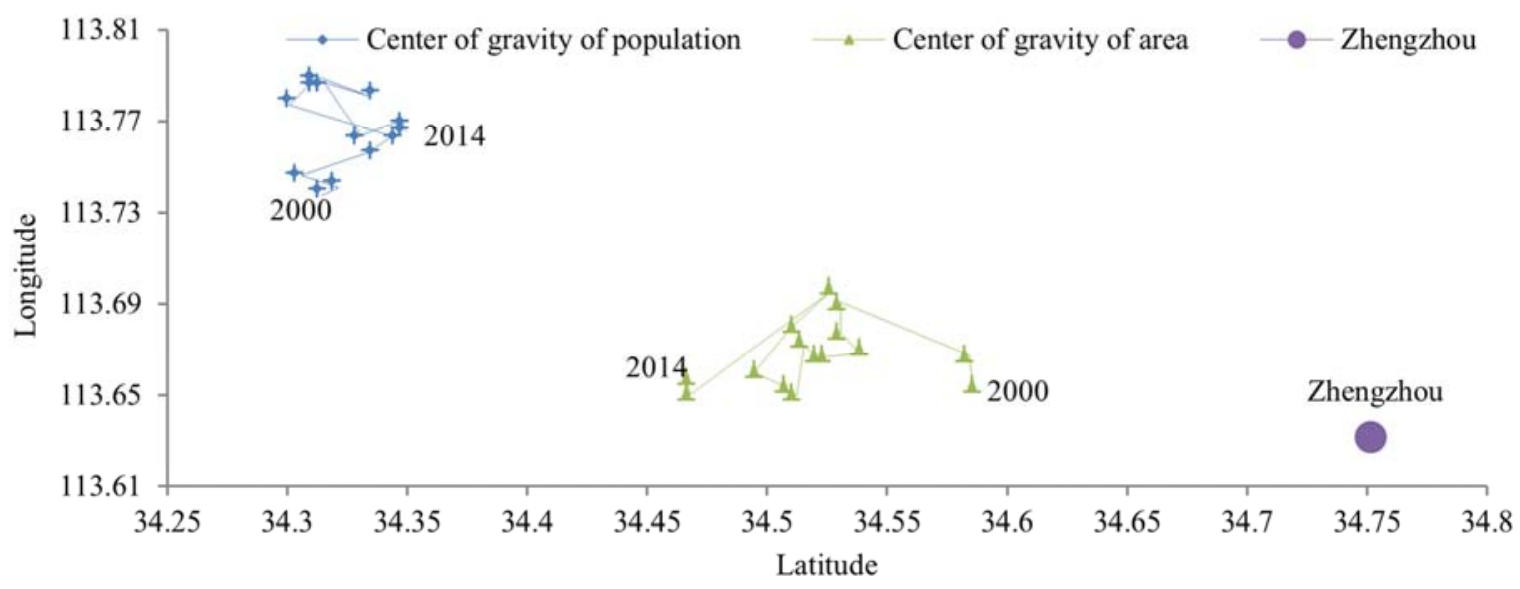

Figure 3. Movement track of center of gravity of urban population and land in Henan Province. 
(2) Overlapping and variation consistency in center of gravity of urban population and land: the distance between center of gravity of population and land showed the variation trend of "declining - stable - declining". It declined from 30 $\mathrm{km}$ in 2000 to $23.32 \mathrm{~km}$ in 2004, and further declined to 16.34 $\mathrm{km}$ in 2014. The overlapping of center of gravity became better and better, and the coupling coordination was also improving. The consistency in movement track of centers of gravity of urban population and land showed "the same direction - opposite direction" alternate changes. Although the consistency was not stable, the consistency index was generally declining, particularly in 2010-2014, the consistency index was below 0 , and the average value was -0.19 , indicating that the center of gravity of urban population and land showed movement in the opposite direction, and the distance between centers of gravity was constantly narrowing. According to Figure 4, we can divide the coupling coordination between urban population growth and land expansion into three stages. The first stage is the year 2000-2004. At this stage, the center of gravity of population moved $4 \mathrm{~km}$ to the northeast, with annual movement of 1.78 $\mathrm{km}$; the center of gravity of land moved $5.48 \mathrm{~km}$ to the southeast, with annual movement of $2.54 \mathrm{~km}$; although the consistency index was above 0 on the whole and the centers of gravity moved in the same direction, the movement of center of gravity of land was faster than that of population, the distance between two centers of gravity was still declining (from $31.13 \mathrm{~km}$ to $23.32 \mathrm{~km}$ ), while the coupling coordination was gradually improving. The second stage is the year 2004-2009. At this stage, the center of gravity of population moved $4.32 \mathrm{~km}$ to the southeast, with annual movement of 1.3 $\mathrm{km}$; the center of gravity of land moved $3.7 \mathrm{~km}$ to the southwest, with annual movement of $1.1 \mathrm{~km}$; the consistency index changed alternately, the average value was -0.05 , the distance between centers of gravity of urban population and land basically kept $25.3 \mathrm{~km}$, and the coupling coordination was relatively stable. The third stage is the year 2009-2014. At this stage, the center of gravity of population moved $4.8 \mathrm{~km}$ to the northwest, with annual movement of $1.7 \mathrm{~km}$; the center of gravity of land firstly moved to the east then to the southwest, and generally moved $4.6 \mathrm{~km}$ to the south, with annual movement of $2.54 \mathrm{~km}$; the consistency index was below 0 , and the centers of gravity moved in the opposite direction, the distance between two centers of gravity was further narrowing, from $25.37 \mathrm{~km}$ to $16.34 \mathrm{~km}$, while the coupling coordination was further improving.

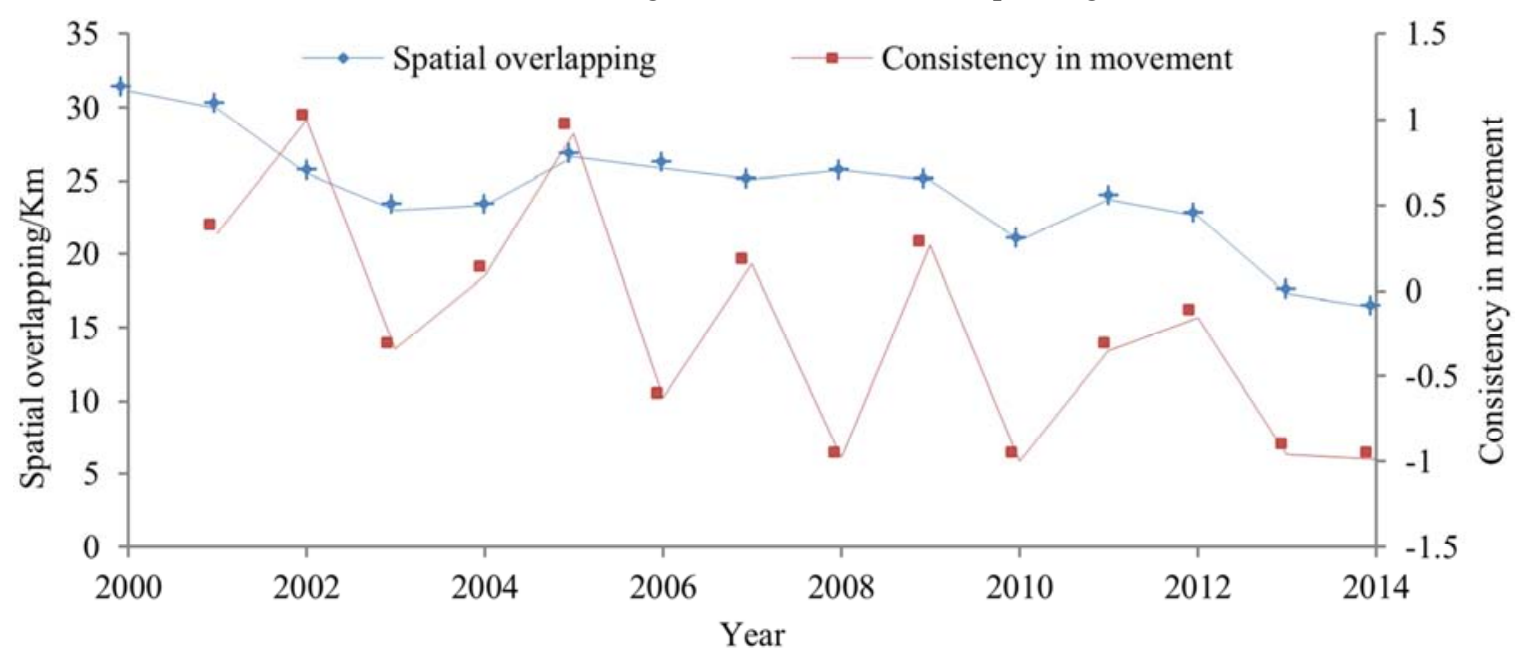

Figure 4. Spatial overlapping and consistency in movement of center of gravity of urban population and land in Henan Province.

\subsubsection{Trend of Spatial Coordination}

With the aid of DEA calculation model, we obtained the ideal values of the urban population, built-up area, and GDP of the cities in Henan Province in 2000-2014, as listed in Table 1 (not all calculation results were indicated): the average annual growth rate of urban population, land, and economy of 18 cities in Henan Province was 17.84\%, 21.51\% and 29.19\% respectively, indicating that these three factors were not changed in the same proportion, the highest growth rate came from the economic scale, followed by the land scale, and the last was the population. Besides, the proportional relationship between urban population size and land scale was constantly changing, and it showed an upward trend on the whole.

Table 1. Optimal values of urban population, land, and economy in Henan Province.

\begin{tabular}{llllllll}
\hline Year & $\mathbf{2 0 0 0}$ & $\mathbf{2 0 0 2}$ & $\mathbf{2 0 0 4}$ & $\mathbf{2 0 0 6}$ & $\mathbf{2 0 0 8}$ & $\mathbf{2 0 1 0}$ & $\mathbf{2 0 1 2}$ \\
\hline Urban population & 48 & 51 & 53 & 63 & 66 & 103 & 443 \\
Built-up area & 27 & 30 & 34 & 36 & 36 & 71 & 373 \\
GDP & 103 & 116 & 155 & 213 & 266 & 481 \\
Population-land ratio & 0.56 & 0.59 & 0.64 & 0.57 & 0.55 & 0.69 & 2812 \\
\hline
\end{tabular}


using the actual values and ideal values of urban population

indicated in Figure 5. and land of 18 cities in Henan Province. The results were

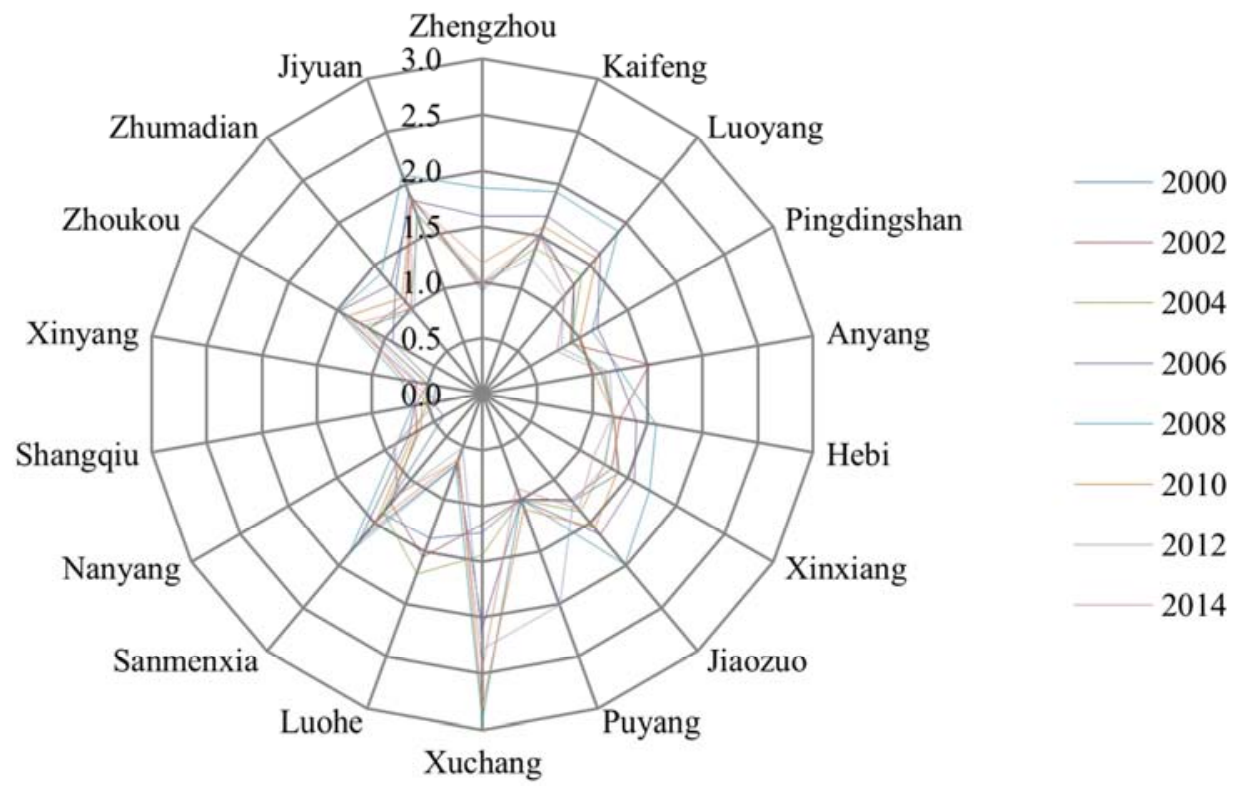

Figure 5. Coordination degree of urban population and land scale in Henan Province.

In order to observe the spatial variation characteristics of every city more visually, we divided the coordination index $(C)$ of every city into 2000-2007 stage and 2007-2014 stage, calculated the average value of each stage, and obtained the spatial distribution maps (Figure 6) for the degree of coordination between urban population and land scale of 18 cities according to the grading standard of the coordination index $(C)$.

(1) 2000-2007: 3 cities had population obviously excessive, accounting for $13.85 \%$ of urban land and $25.77 \%$ of urban population; 4 cities had basically coordinated population and land, accounting for $33.83 \%$ of urban land and $32.57 \%$ of urban population; 9 cities had land obviously excessive, accounting for $45.87 \%$ of urban land and $38.26 \%$ of urban population; 2 cities had land significantly excessive, accounting for $6.46 \%$ of urban land and $3.4 \%$ of urban population.

(2) 2007-2014: only one city had population significantly excessive, accounting for $3.28 \%$ of urban land and $8.1 \%$ of urban population; 3 cities had population obviously excessive, accounting for $16.19 \%$ of urban land and $21.21 \%$ of urban population; 4 cities had basically coordinated population and land, accounting for $16.03 \%$ of urban land and $17 \%$ of urban population; 8 cities had land obviously excessive, accounting for $57.62 \%$ of urban land and $50.06 \%$ of urban population; 2 cities had land significantly excessive, accounting for $6.88 \%$ of urban land and $3.09 \%$ of urban population.

(3) In 2000-2014, the coordinated development level of every city remained basically unchanged. Cities with excessive development of population included Nanyang, Xinyang, Shangqiu and Luohe, in which Luohe changed from a city with coordinated population and land to a city with excessive population, while Shangqiu had aggravation of excessive population. These cities were mainly distributed in edge areas of Henan Province, had large administrative area, large population, but relatively backward urbanization. There were great changes in cities with basically coordinated population and land. Zhengzhou changed from a city with basically coordinated population and land to a city with excessive development of land, while Anyang and Zhumadian changed from cities with excessive development of land to cities with basically coordinated population and land.

On the whole, in 2000-2014, the coordination between built-up area and population size of 18 cities in Henan Province was weak, near 11 cities had excessive development of land, accounting for $60 \%$ of the total cities, $65 \%$ of the urban population and $54 \%$ the built-up area. For the spatial distribution, cities with excessive development of land were concentrated in areas along the Beijing-Kowloon Railway and economically developed areas with Zhengzhou as the center and Luoyang and Kaifeng as sub-centers. These areas were also core regions of Central Plains city clusters, their economy developed rapidly, and the demand of urban construction land was high, so there were many cities with land expansion. However, there were few cities with basically coordinated population and land and excessive development of population, the former was sporadically distributed, while the latter was mainly distributed in edge areas of Henan Province, weakly influenced by radiation of core city clusters, had large agricultural population, and weak comprehensive strength. On the whole, Henan Province remained at the stage of excessive development of land, the per capita construction land area was very low, it increased from $51.6 \mathrm{~m}^{2}$ in 2000 to $86 \mathrm{~m}^{2}$ in 2014 , the development was fast, but the overall development scale was small. 

Land Expansion in Henan Province
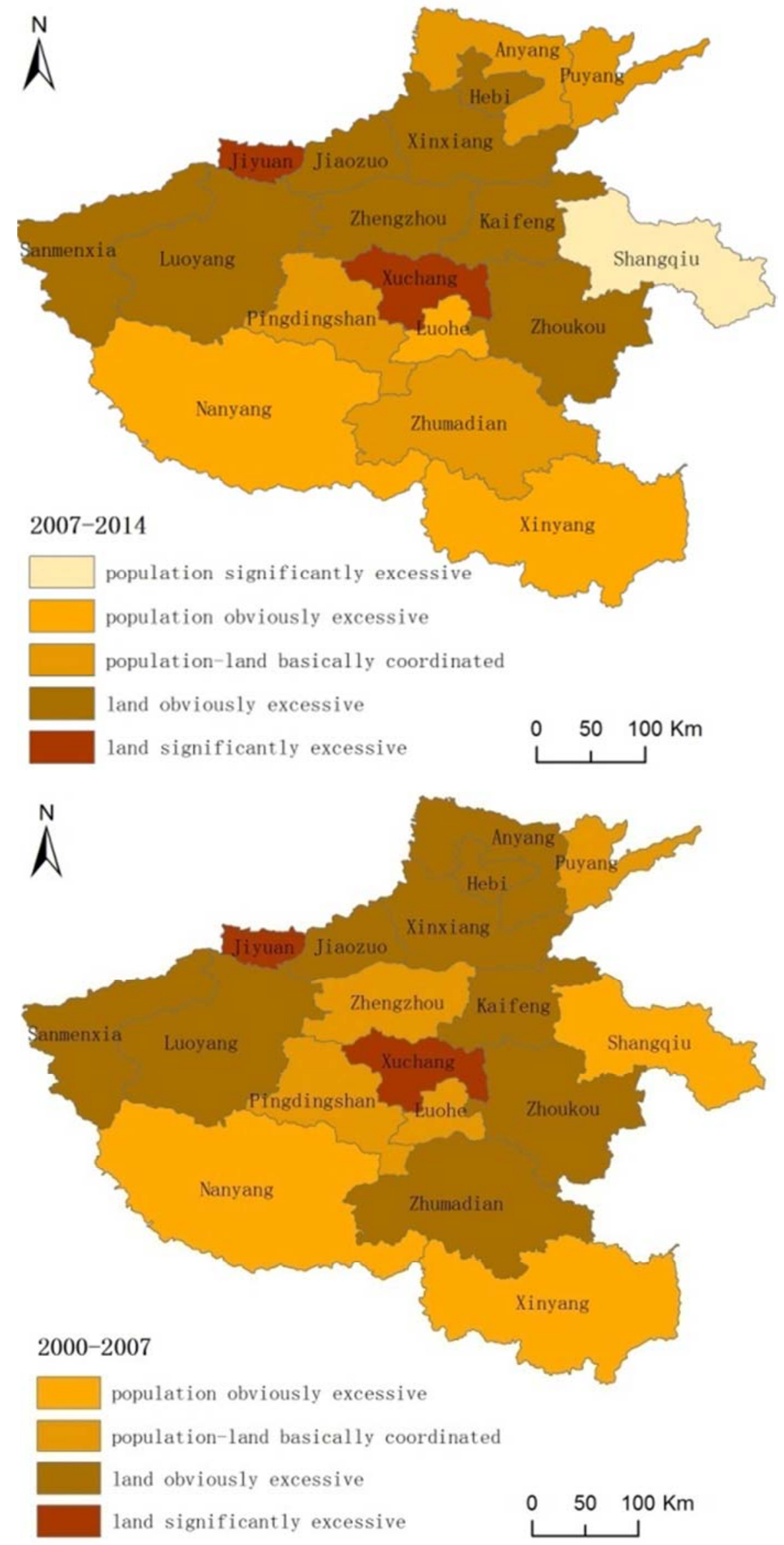

Figure 6. Spatial pattern for coordination degree of urban population and land scale in Henan Province. 


\subsection{Prediction of Urban Population and Land Growth in Henan Province}

Urban development has its inherent rules, and the government policy-leading urbanization will inevitably affect the natural rules of urban development. Since the coordination measure model only analyzes the urban population and land relationship at the current stage, it is impossible to predict the trend of their changes, and it is not favorable for control of city size and formulation of future development plan. Therefore, we used Logistic model to predict the development trend of urban population and land, so as to provide certain reference for scientifically promoting new urbanization in Henan Province. Comparatively speaking, the longer the sample sequence, the more accurate the Logistic prediction results. Thus, we predicted the maximum urban population size and land scale and development trend according to urban population and built-up area in $1985(t=0)-2014(t=29)$. The results are as follows:

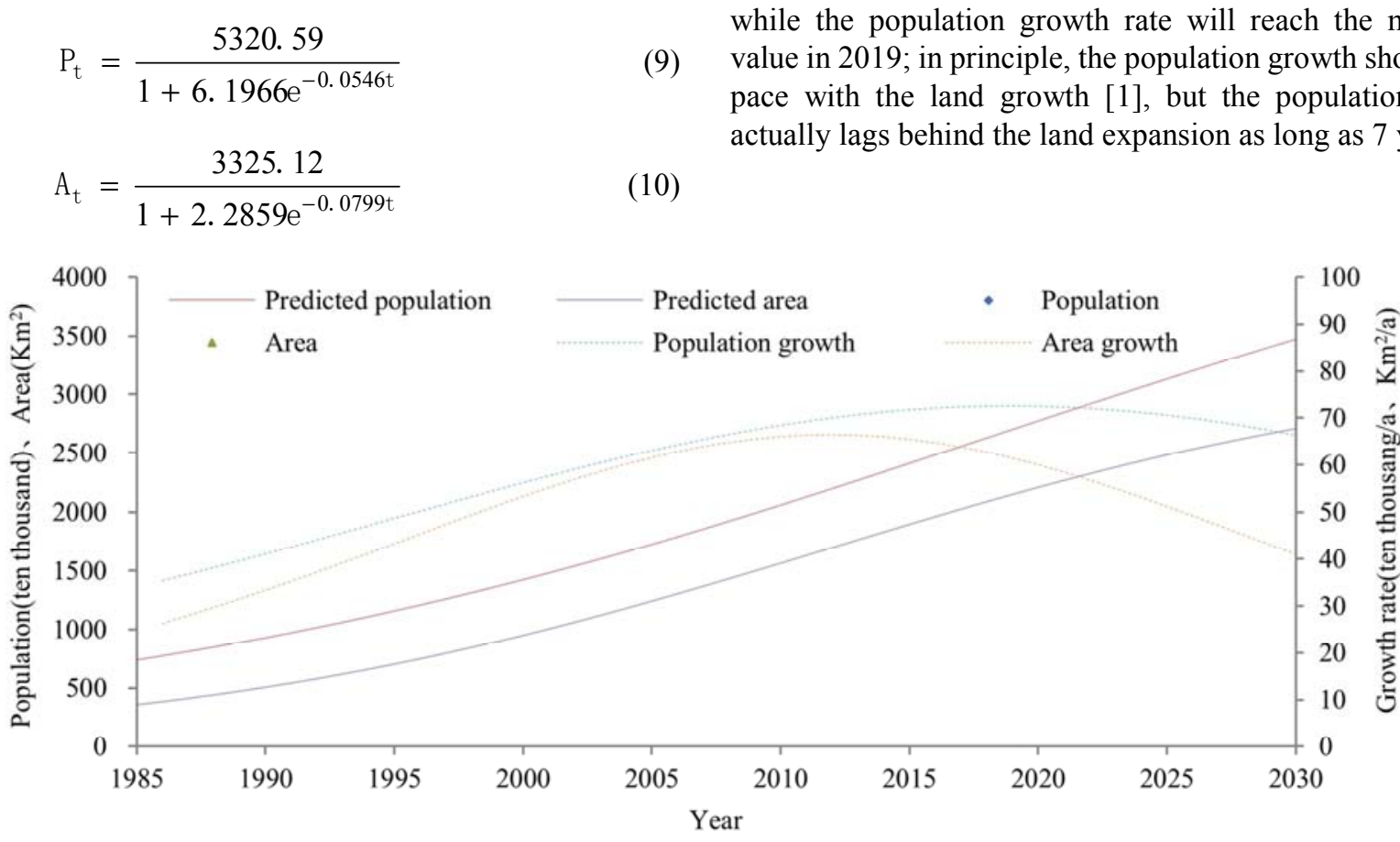

Figure 7. Logistic growth curve and rate changes of urban population and area in Henan Province (1985-2030).

The reasons for population growth lagging behind the land expansion are possibly: in 2013, Henan Province proposed the strategic idea of developing Central Plains city clusters; also in 2013, the construction of Zhengdong New District of Zhengzhou raised the curtain of rapid urbanization construction of Henan Province, then Henan Province entered the stage of rapid development of urbanization; however, rapid urban expansion broke inherent rules and features of urbanization, and urban land originally lagging behind started exceeding the urban population. Therefore, we assumed that the population growth changed in pace with the land expansion before 2003. Using the data of 1985-2002, we refitted the Logistic growth model (because $S_{\max }$ obtained where $P_{\mathrm{t}}$ denotes the population, and $A_{\mathrm{t}}$ denotes the built-up area. The goodness of fit $\left(R^{2}\right)$ of both functions was higher than 0.98, showing reliable results. As shown in Figure 7, the prediction results were well consistent with the actual results, and can be used to refit the urban population and built-up area in Henan Province in 1985-2014 and predict the limit value of urban development scale and the development trend of future 15 years or so. According to prediction results, the maximum urban population is 53.2 million, the maximum land scale is $3,325 \mathrm{~km}^{2}$, the per capita construction land is $62.5 \mathrm{~m}^{2}$, showing intensive land use; by 2030, the urban population and land scale of Henan Province will reach 34.74 million and $2,710 \mathrm{~km}^{2}$ respectively, and the per capita construction land will be $78 \mathrm{~m}^{2}$, showing some decline compared with the year 2014. In the aspect of growth rate, when the urban population and land scale reached the half of maximum value, the growth rate was the highest. Before reaching the half value, it showed acceleration; after reaching the half value, it showed deceleration. In 2012, the land expansion was the fastest, while the population growth rate will reach the maximum th should keep pace with the land growth [1], but the population growth actually lags behind the land expansion as long as 7 years. from formula (9) and formula (10) is credible, it is unnecessary to refit $S_{\max }$ ), and the results are as follows:

$$
\begin{aligned}
P_{t} & =\frac{5320.59}{1+6.3325 \mathrm{e}^{-0.0573 t}} \\
A_{t} & =\frac{3325.12}{1+7.4206 \mathrm{e}^{-0.0611 \mathrm{t}}}
\end{aligned}
$$

The goodness of fit $\left(R^{2}\right)$ of the model was above 0.99, showing excellent fitting effect. As shown in Figure 8, if the urban population growth and land expansion are not deviating from the trend before 2003, the growth rate of both will reach 
the maximum value in 2018. According to prediction results, in 2014, the urban land scale of Henan Province will be 1,470 $\mathrm{km}^{2}$, the population will reach 24.17 million, the per capita construction land will be $60.8 \mathrm{~m}^{2}$, but the actual urban population lagged behind the prediction value about 1.9 million, and actual land scale exceeded the prediction value about $451 \mathrm{~km}^{2}$, indicating that the policies such as Central Plains city cluster plan and acceleration of urbanization construction are main factors leading to the imbalance between urban population growth and land expansion, so the above assumption holds true.

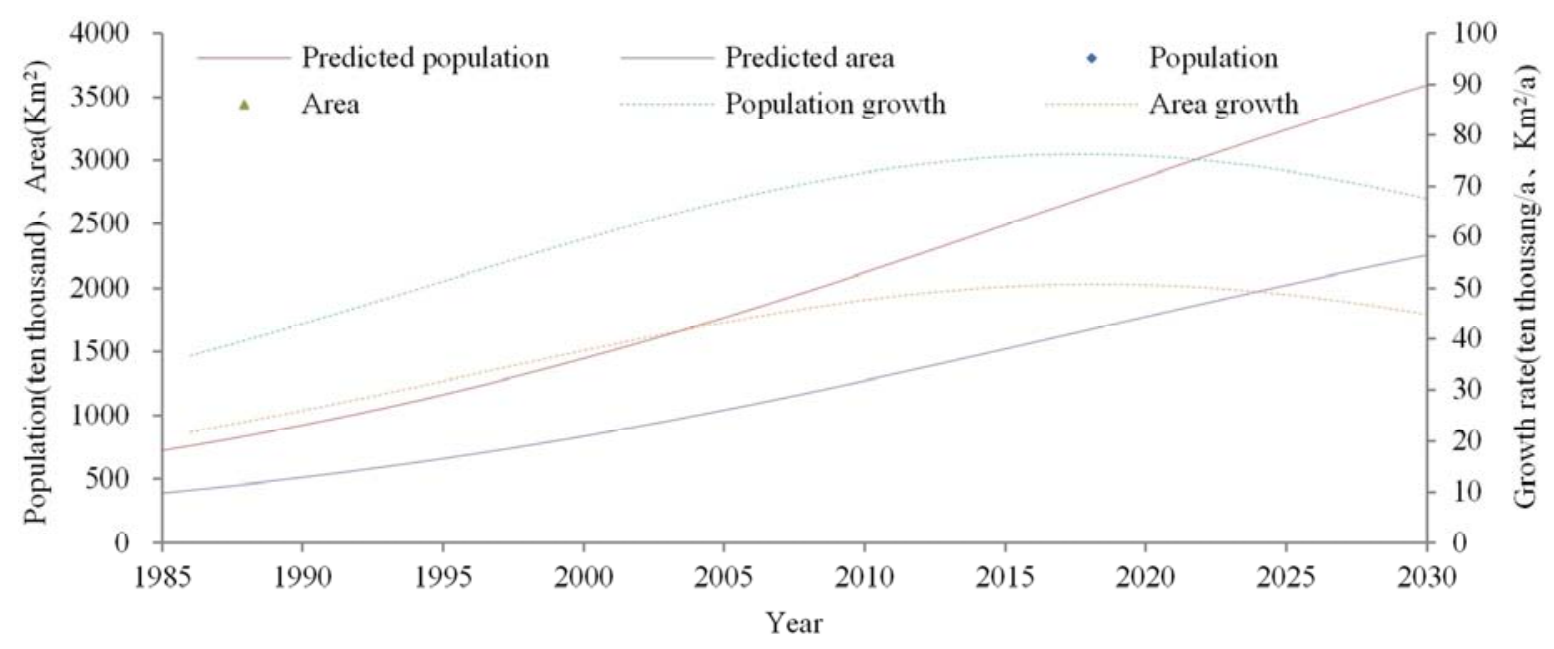

Figure 8. Logistic growth curve and rate changes of urban population and area in Henan Province (1985-2030).

In sum, in 1985-2002, the urban population growth basically kept coordinated with the land expansion speed and scale, and the development of both basically kept in pace with each other. After 2003, with the development of China's urbanization and the policy support of the construction of Central Plains city clusters, the urban industrialization process and economic development level of Henan Province have been rapidly improving, which provides a powerful force for development of urban modernization. However, because of perspective and lagging of urban plan, such government-leading top-down urbanization construction will inevitably lead to the population growth slower than the land expansion in a certain period, consequently leading to the land expansion ahead of the population growth for 7 years and making it more difficult to predict the urban development trend. According to the limit scale and the per capita land area obtained on the basis of population and land in 2014, the ideal per capita land area is $60-65 \mathrm{~m}^{2}$. According to prediction results of formula (9) and formula (10), in future 16 years, the urban population increase will be 12.47 million, the land scale increase will be $789 \mathrm{~km}^{2}$, the increment of per capita land area is $63.3 \mathrm{~m}^{2}$, which is in the ideal range, indicating that urban population growth of Henan Province will enter the stage of acceleration, while the built-up area expansion will enter the stage of deceleration, and the growth scale of both will return to the reasonable state. Local government should deepen the innovation of system and mechanism and formulate scientific plan for new urbanization development in the process of urbanization construction, and promote the new urbanization in a people-oriented manner.

\section{Conclusions}

In this study, we mainly applied the data envelope analysis
(DEA) to build urban population and land expansion coordination evaluation model, analyzed the development changes and coordination relationship between population growth and land expansion in different time and 18 cities of Henan Province, and used Logistic model to predict the development trend of urban population growth and land scale in Henan Province. We obtained following results:

(1) On the whole, in 2000-2014, both the urban population and land scale realized rapid growth, but the land expansion was significantly faster than the population growth, and urban population density declined year by year. In the spatial distribution, the urban population growth and land expansion showed "core-edge" circle characteristics, with major growth in core cities such as Zhengzhou, Luoyang, and Luohe, and auxiliary growth in edge cities such as Anyang, Nanyang, and Xinyang. Generally, the land expansion was faster than the population growth, but the distribution of urban land density was basically consistent with the distribution of population density, indicating a high correlation between them.

(2) The coordination relationship between land expansion and population growth of 18 cities in Henan Province was constantly changing. Firstly, the center of gravity of both urban population and built-up area in Henan Province was in southeast of Zhengzhou, and the coordination relationship between them showed the "enhancing - stable - enhancing" trend. Specifically, in 2000-2004, the center of gravity of population moved to the northeast, while the center of gravity of land moved to the southeast, and the coordination between them was gradually enhancing; in 2004-2009, the center of gravity of population moved to the southeast, while the center of gravity of land moved to the southwest, and the coordination between them kept stable; in 2009-2015, the center of gravity of population moved to the northwest, while the center of gravity of land firstly moved to the east and then 
to southwest, and the coordination between them was further enhancing. Secondly, from the perspective of characteristics of spatial coordination and distribution pattern, the coordination between land scale and population size of 18 cities in Henan Province was weak, the land development was excessive, but the per capita construction land area did not exceed the standard specified by the state. Cities with excessive development of land were mainly concentrated in the core regions of Central Plains city cluster with Zhengzhou as the center; there were few cities with coordinated population-land relationship and excessive population growth; the former took on scattered distribution, while the latter was mainly distributed in edge regions of Henan Province.

(3) Logistic prediction results: the maximum urban population is 53.2 million, the maximum land scale is 3,325 $\mathrm{km}^{2}$, the ideal per capita land area is $60-65 \mathrm{~m}^{2}$; before 2003 , the urban population growth kept in pace with land expansion in Henan Province; after 2003, due to government plans such as construction of Central Plains Economic Region and the rise of central regions, urban land is rapidly expanding and ahead of the population growth for 7 years; in 2030, the urban population will be 34.74 million, land scale will be $2,710 \mathrm{~km}^{2}$, the per capita land area will be $78 \mathrm{~m}^{2}$, such results are credible. In 2015-2030, the increment of per capita land area is $63.3 \mathrm{~m}^{2}$, which is in the ideal range, indicating that the growth of urban population and land expansion will become coordinated in future.

\section{Acknowledgements}

Great gratitude to the fund support of the National Natural Science Foundation of China (41771565), Henan provincial government decision research tendering project (2017B189), Henan Province Philosophy and Social Science Planning Project (2014BJJ001).

\section{References}

[1] Chan, R. C. K., Yao, S. M., 1999. Urbanization and sustainable metropolitan development in China: Patterns, problems and prospects. GeoJournal 3, 269-277.

[2] Chen, X. F., Yao, S. M., Zhang, L. C., 2016. The Theory and Practice of Urban-Rural Integration in China Under the New Urbanization. Scientia Geographica Sinica 36, 188-195 (In Chinese).

[3] Lyu, T. G., Wu, C. F., Li, H. Y., You, H. Y., Cai, X., 2016. The Coordination and Its Optimization About Population and Land of Urbanization:A Case Study of Nanchang City. Scientia Geographica Sinica 36, 239-246 (In Chinese).

[4] Niu, S. W., Lan, Z. C., Hu, Y. Y., 2014. Urbanization: Population Growth Constranit and Policy Implication. China Population, Resources and Environment 24, 49-56 (In Chinese).

[5] Feng, Z. M., Yang, Y. Z., You, Z., Zhang, J. H., 2014. Research on the suitability of population distribution at the county level in China. Acta Geographica Sinica 69, 723-737 (In Chinese).
[6] Lu, D. D., Yao, S. M., Li, G. P., Liu, H., Gao, X. L., 2007. Comprehensive analysis of the urbanization process based on China's conditions. Economic Geography 27, 883-887 (In Chinese).

[7] Yang, Y. Z., Feng, Z. M., Zhao, Y, D., You, Z., 2013. Coordination between urban land expansion and population growth in China. Geographical Research 32, 1168-1678 (In Chinese).

[8] Chen, Y. G., Zhang, L., 2014. An allometric analysis of the scaling relations between population and urban area of Xinyang. Progress in Geography 33, 1058-1067 (In Chinese).

[9] Fu, J. C., Li, G., Zhao, H., Zhang, J. Y., 2015. Relation Between the Population and the Land Area of Urban Built-up Area in China: An Empirical Research of 652 Counties. Chain land sciences 29, 46-53 (In Chinese).

[10] Wang, C. X., Wang, B. T., Wang, X. Y., 2016. Study on population urbanization and land urbanization allometric growth in China based on the structure. China Population, Resources and Environment 8, 135-141 (In Chinese).

[11] Zhou, Y., Huang, X. J., Xu, G. L., Li, J. B., 2016. The coupling and driving forces between urban land expansion and population growth in Yangtze River Delta. Geographical Research 35, 313-324 (In Chinese).

[12] Chen, M. X., Tang, Z. P., Bai, Y. P., 2013. Relational pattern of urbanization and economic development:The parameter revaluation of Chenery's Model. Acta Geographica Sinica 68, 739-749 (In Chinese).

[13] Fan, H., Liu, W. D., Wu, Z. B., Zhang, H. Y., 2014. The Coupling Coordination Evaluation between Population Urbanization and Land Urbanization in Zhejiang Province. Economic Geography 34, 21-28 (In Chinese).

[14] Cui, X. F., 2014. Population Urbanization and Land Urbanization in Ethnic Minority Areas: Disequilibrium and Spatial Heterogeneity. China Population, Resources and Environment 34, 21-28 (In Chinese).

[15] Huang, J. B., Feng, C. C., 2015. Assessment of Coordinate Development among Population, Economy and Land Urbanization Based on Pareto Optimality:A Case Study of Cities along the Yangtze River in Anhui Province. Modern Urban Research 10, 65-69 (In Chinese).

[16] Zhong, Y. X., Feng, X. H., Song, L., Wu, W., 2016. Urban Land Expansion and Population Growth in Mountain and Hilly Regain of Southern JiangXi. Mountain Research 34, 485-495 (In Chinese).

[17] Tian, S. Y., Xu, W. L., 2012. Evaluation of China's forestry input-output efficiency based on DEA modeling. Resources Science 34, 1944-1950 (In Chinese).

[18] United Nations. Methods for Projections of Urban and Rural Population. Population Studies, 1974.

[19] Chen, Y. G., 2009. Carrying capacity estimation of Logistic model in population and resources prediction by nonlinear autoregression. Journal of Natural Resources 24, 1105-1114 (In Chinese).

[20] Liu, Y. S., Deng, X. S., Gan, H., 2005. The state and optimization counter measures of urban land-use in China. Journal of Chongqing Jianzhu University 27, 1-4 (In Chinese). 